REVISIÓN

\title{
Presencia del camarón tigre gigante Penaeus monodon (Decapoda: Penaeidae) en las costas del Atlántico Americano. Revisión
}

\author{
Presence of the giant tiger shrimp Penaeus monodon (Decapoda: Penaeidae) from \\ American Atlantic coasts. Review
}

\begin{abstract}
Gabriel Aguirre-Guzmán ${ }^{1 *}$ y Edgar A. López- Acevedo ${ }^{1}$
${ }^{1}$ Facultad de Medicina Veterinaria y Zootecnia, Universidad Autónoma de Tamaulipas, Km 5 Carr. Victoria-Mante, Ciudad Victoria, Tamaulipas, México

*Autor corresponsal: gabaguirre@docentes.uat.edu.mx

Abstract.- The presence of invasive species is an important element with high relevance associated to their impact on the environment. The aim of this work was to collect scientific information about a new invasive species (Penaeus monodon) reported on the Mexican coasts (2012), their possible origin, distribution mechanisms on the coasts of the American Atlantic, and their potential risk to the ecosystem. Historical scientific information about P. monodon in the American Atlantic showed that it was transported to Brazil and USA in 1987-1988 for aquaculture purposes, where escapes were reported. Penaeus monodon adults have been detect in coast of Brazil, Colombia, Costa Rica, Cuba, Guatemala, Mexico, USA and Venezuela from 1987 to 2016 . Those results suggest the establishment of this specie in the American Atlantic Oceans. The evidence also indicates that $P$. monodon is an important competitor of space and food compared to local shrimp species, predator of other crustacean's species and reservoir/transport of different pathogens like viruses, bacteria, and parasites. Additional studies and monitoring are required to assess and understand the population dynamics of this species in American Atlantic waters, their mechanisms of distribution, potential impact of this exotic species and their growth on the native biota, and their relevance as a natural reservoir of viral pathogens that affect the production of wild shrimp and culture.
\end{abstract}

Key words: Penaeus monodon, tiger shrimp, invasive species, Atlantic Ocean

\begin{abstract}
Resumen.- La presencia de especies invasoras es un tema que está adquiriendo gran importancia debido al efecto en el medio ambiente que pueden generar. El objetivo del presente trabajo fue colectar información cientifica sobre una nueva especie invasora (Penaeus monodon) reportada en las costas mexicanas (2012), mostrando su posible origen, mecanismos de dispersión en las costas del Atlántico Americano y el riesgo potencial para el ecosistema. La información científica histórica sobre P. monodon en el Atlántico Americano señala que fue trasladado a Brasil y EUA en 1987-1988 con fines de cultivo, donde además se reportaron fugas de esta especie. Desde 1987 al 2016 se han detectado adultos silvestres de P. monodon en Brasil, Colombia, Costa Rica, Cuba, EUA, Guatemala, México, y Venezuela, lo que sugiere el establecimiento de esta especie en las aguas del Atlántico Americano. La evidencia también señala que $P$. monodon es un importante competidor de espacio y alimento de especies locales de camarón, posible depredador de otros crustáceos y reservorio / vehículo de diferentes agentes patógenos (virus, bacterias y parásitos). Es importante profundizar en las investigaciones sobre la dinámica poblacional que presenta esta especie en aguas del Atlántico Americano, sus mecanismos de distribución, consecuencias potenciales que puede generar su crecimiento poblacional sobre la biota nativa, además de su importancia como reservorio natural de agentes patógenos virales que afecten la producción de camarón silvestre y de cultivo.
\end{abstract}

Palabras clave: Penaeus monodon, camarón tigre, especie invasora, Océano Atlántico

\section{INTRODUCCIÓN}

Los organismos comúnmente denominados camarones, están representados por 2.000 especies del suborden Natania, los cuales pueden ser carnívoros, detrítívoros, herbívoros, u omnívoros. Estos crustáceos habitan en aguas estuarinas o marinas, lagos, ríos y algunos han sido empleados en la acuacultura mundial. FAO (2018) señala la producción de 4.170.000 ton métricas de estos organismos para el 2016, lo cual lo sitúa como un producto acuícola de gran relevancia para muchos países.
El volumen de producción de algunas especies de camarón se ha destacado en diversos países, así como el interés por aumentar la producción de alimento, ingreso económico, o para solventar problemas como las enfermedades que afectan a estos organismos. Litopenaeus vannamei (Boone, 1931), L. stylirostris (Stimpson, 1874), Marsupenaeus japonicus (Bate, 1888) y P. monodon (Fabricius, 1798) son las especies más empleadas en la acuacultura mundial. Estas tendencias han propiciado la intensificación de los sistemas productivos, además de 
promover el interés de diversos productores de trasladar las especies comerciales a regiones donde no habitan normalmente a fin de evaluar su adaptabilidad, uso potencial en producción acuícola, y factibilidad económica-comercial con los consumidores. Por ejemplo, P. monodon fue una de las principales especies empleadas en acuacultura entre 1970 a 1980 (Shigueno 1985, Aguirre-Pabón et al. 2015) y la especie fue trasladada a América para el uso experimental y de cultivo (Tabla 1). Sin embargo, el interés decayó debido a que no se lograron resultados deseados, sumado al reporte de fugas de los organismos a partir de su cautiverio en granjas y posteriores avistamientos en el medio silvestre (Wyban \& Arki 1989, Briggs et al. 2005, Villac et al. 2009, Rodríguez-Almaraz \& García-Madrigal 2014). Por su parte, L. stylirostris y L. vannamei fueron exportadas desde América hacia Asia con fines de investigación y cultivo comercial (Briggs et al. 2004, 2005; Wyban 2010, Lightner 2012), siendo L. vannamei la especie más exitosa en los cultivos de China, India, y Tailandia entre otros. Esto convirtió a $L$. vannamei en el camarón de mayor cultivo a nivel mundial (Briggs et al. 2004, 2005; FAO 2018).

Los procesos que conllevan a una economía globalizada están fuertemente vinculados a un intenso comercio y un vertiginoso flujo de productos fuera de sus áreas tradicionales de producción. El transporte de productos congelados y organismos vivos fuera de las fronteras de cada país derivando en una gran expansión de los productos con fines comerciales o investigación, pero sin conocer a fondo los riesgos al medio ambiente de estas movilizaciones intensivas y globales. Ocasionalmente, algunas especies exóticas que fueron trasladadas vivas disminuyen debido a la fuga de algunos especímenes, los cuales se reproducen y diseminan, invadiendo el nuevo ambiente al encontrarse en un medio favorable de desarrollo y libre de sus depredadores naturales. Este fenómeno facilita la formación de nuevas poblaciones, generando problemas al medio ambiente cuando las especies exóticas invasoras compiten con las especies locales por alimento y espacio. Otro problema que pueden tener estas especies exóticas invasores es cuando contienen patógenos que también pueden ser liberados al medio ambiente. Este fenómeno se ha sugerido para P. monodon, denominado como camarón tigre gigante o camarón tigre asiático, quien se le ha considerado como una nueva especie exótica invasora para México (RodríguezAlmaraz et al. 2014). Este organismo fue trasladado a América en décadas pasadas para su uso en acuacultura de investigación y comercial (Tabla 1) y donde presuntamente existieron fugas accidentales, siendo continuamente reportada su captura en medio silvestre por pescadores de diversos países en el Atlántico Americano (Tabla 2, Fig. 1). Un fenómeno similar se presentó en Tailandia cuando L. vannamei fue cultivado en 1999 ante la insistencia de granjas comerciales (Tookwinas et al. 2005) y en las cuales también se presentaron fugas de esta especie de camarón con la posterior captura en el sistema lagunar del río Bang pakong, Tailandia (Senanan et al. 2007). La presencia de $L$. vannamei en medio silvestre puede representar un posible reservorio de Taura Syndrome Virus (TSV) y otros patógenos exóticos, además de ser un competidor activo de las especies locales por alimento y espacio como lo señalan Senanan et al. (2009). Por otro lado, Nielsen et al. (2005) y Ruangsri et al. (2005) indicaron que las autoridades tailandesas consideraron que uno de los mayores problemas del cultivo de L. vannamei era el posible traslado de agentes virales americanos [e.g., Infectious Hypodermal and Haematopoietic Necrosis Virus (IHHNV) y TSV, siendo algunas especies nativas susceptibles a infecciones por estos virus [Macrobrachium equideus (Dana, 1852), M. lanchesteri (De Man, 1911), M. rosenbergii (De Man, 1879), Metapenaeus monoceros (Fabricius, 1798),

Tabla 1. Reportes sobre la introducción de Penaeus monodon en diferentes países para su uso en acuacultura / Reports about Penaeus monodon introduction in different countries for use in aquaculture

\begin{tabular}{|c|c|c|c|}
\hline & País & Localidad & Referencia \\
\hline 1976 & EUA y Panamá & & Welcomme 1988 \\
\hline 1977 & Brasil & Río Potengí, Natal & Villac et al. (2009) \\
\hline 1984 & Venezuela & Sistema lagunar de Maracaibo & Rodríguez \& Suárez (2001) \\
\hline 1985 & Brasil & Canguaretama y Bahía & $\begin{array}{l}\text { Briggs et al. (2004), Tavares \& Braga (2004), } \\
\text { Villac et al. (2009) }\end{array}$ \\
\hline 1985 & República Dominicana & & Welcomme 1988 \\
\hline 1986 & Cuba & Tunas de Zaza, Golfo de Ana María & Giménez et al. (2013) \\
\hline \multirow[t]{2}{*}{1988} & EUA & Hawái & $\begin{array}{l}\text { Wyban \& Arki (1989), Rodríguez-Almaraz } \\
\text { \& García-Madrigal et al. (2014), Briggs et al. } \\
(2004)\end{array}$ \\
\hline & & Carolina del Sur & Avalos (2015) \\
\hline 1988 & Cuba & & Coto $(2005)$ \\
\hline
\end{tabular}


Tabla 2. Reportes de Penaeus monodon capturados por pescadores en diferentes países / Reports of Penaeus monodon captured by fishermen in different countries

\begin{tabular}{|c|c|c|c|c|c|c|}
\hline & País & Localidad & Talla (cm) & Peso (g) & Sexo & Referencia \\
\hline 1987 & Brasil & Praia de Tutóia, Maranhäo & 29 & 200 & 우 & Fausto-Filho (1987) \\
\hline 1988 & EUA & Carolinas, Georgia, y Florida & - & - & - & Fuller et al. (2014) \\
\hline \multirow[t]{2}{*}{2001} & Brasil & Laguna de Mundaú, Alagoas, y Pernambuco & $21,5-24,0$ & $79-104$ & $\hat{o}$ & Coelho et al. (2001) \\
\hline & & & 25,0 & 230 & q & “ \\
\hline \multirow[t]{2}{*}{$2000-2002$} & Brasil & Barra de Sirinhaém & $22,9-24,7$ & $100-130$ & 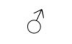 & Santos \& Coelho 2002 \\
\hline & & Lagoa Manguaba & 24,2 & 223 & q & “ \\
\hline \multirow[t]{2}{*}{ 2004-2005 } & Venezuela & Río Orinoco y Golfo de Paria & $17,2-28,4$ & $38-172$ & 우 & Altuve et al. (2008) \\
\hline & & & $24,5-31,0$ & $117-314$ & q & “ \\
\hline 2005 & Colombia & Cabo de la Vela (Península de Guajira) & $6,8-8,8$ & & q & $\begin{array}{l}\text { Gómez-Lemos \& Hernando } \\
\text { Campos (2008) }\end{array}$ \\
\hline \multirow[t]{2}{*}{ 2006-2007 } & Venezuela & Píritu y Barcelona, Anzoátegui & $18,0-24,0$ & $55-70$ & q & Aguado \& Sayegh (2007) \\
\hline & & & $16,0-18,0$ & $25-42$ & $\delta$ & “ \\
\hline 2006-2012 & EUA & Carolinas, Georgia, Alabama, Mississippi, Luisiana, Florida y Texas & $10,2-29,8$ & - & - & Fuller et al. (2014) \\
\hline 2008 & Cuba & Santa Cruz del Sur & 30,0 & - & - & Giménez et al. (2014) \\
\hline \multirow[t]{2}{*}{2008} & Colombia & Punta Gallinas (Península de Guajira) & 7,5 & - & q & $\begin{array}{l}\text { Gómez-Lemos \& Hernando- } \\
\text { Campos (2008) }\end{array}$ \\
\hline & & & $16,0-18,0$ & $25-42$ & $\sigma^{\pi}$ & " \\
\hline \multirow[t]{2}{*}{2010} & Brasil & Estado de Para & 21,7 & 84,6 & 우 & Hidenburgo et al. (2011) \\
\hline & & Estados de Amapá & $25,0-37,0$ & $135-286$ & $q$ & Silva et al. (2002) \\
\hline 2010 & Cuba & Zona de Júcaro & $10,6-20,0$ & - & $q \hat{\sigma}$ & Giménez et al. (2014) \\
\hline 2011 & Cuba & Tunas de Zaza, Golfo de Ana María & $27,0-29,0$ & $140-230$ & q & Giménez et al. (2013) \\
\hline 2011 & Colombia & $\begin{array}{l}\text { Golfo de Urabá, Cabo de La Vela, Ciénaga Grande de Santa Marta, } \\
\text { Cartagena, Córdoba }\end{array}$ & - & $50-500$ & - & $\begin{array}{l}\text { Medellín et al. (2011), } \\
\text { Sandoval et al. (2014) }\end{array}$ \\
\hline 2012 & Brasil & Río Grande del Norte & 25,0 & 173 & q & Morais et al. (2015) \\
\hline 2012 & Colombia & Golfo de Salamanca (Península de Magdalena) & - & - & - & Aguirre-Pabón et al. (2015) \\
\hline \multirow[t]{2}{*}{$2012-2013$} & México & Tamaulipas & $29,0-31,0$ & $189-276$ & $\delta$ & Wakida-Kusunoki et al. (2013) \\
\hline & & Campeche & $25,0-29,0$ & $116-276$ & $\hat{\sigma}$ & “ \\
\hline 2013 & Brasil & Foz do Río Pará, & $25,0-28,8$ & $114-169$ & q & Aniceto et al. (2014) \\
\hline \multirow[t]{2}{*}{2014} & México & Veracruz & - & - & - & Morán-Silva et al. (2014) \\
\hline & & Yucatán & $21,0-29,0$ & $111-200$ & ๑ठ & Wakida-Kusunoki et al. $(2016 a, b)$ \\
\hline \multirow[t]{2}{*}{2014} & Costa Rica & Río Colorado & - & $59-119$ & $\delta$ & Alfaro-Montoya et al. (2015) \\
\hline & & & - & $107-187$ & q & “ \\
\hline \multirow[t]{2}{*}{2014} & Guatemala & Bahía de Amatique & $26,3-32,6$ & $163-226$ & 우 & Avalos 2015 \\
\hline & & & $13,2-28,0$ & $60-197$ & $\hat{\sigma}$ & “ \\
\hline 2016 & EUA & Bahía de Vizcaine & $4,7-12,9$ & & & Zink et al. (2018) \\
\hline
\end{tabular}

P. monodon y Scylla serrata (Forskål, 1775)]. Ambos virus fueron detectados años después en Tailandia y otros países asiáticos (Briggs et al. 2005, Senanan et al. 2007). Wakida-Kusunoki et al. (2011) reportaron la presencia de L. vannamei en el complejo lagunar Carmen-PajonalMachona, Tabasco, México, señalando que las granjas de acuacultura ahí presentes pueden ser el origen de estos organismos detectados en el medio silvestre y que pueden generar impacto en el medio ambiente.

Wakida-Kusunoki et al. (2011, 2013), Morán-Silva et al. (2014), y Wakida-Kusunoki et al. (2016a, b) reportaron la presencia de $P$. monodon en las costas de Campeche, Tabasco, Veracruz y Yucatán, México, mientras que, en La Pesca, Soto la Marina, Tamaulipas, México se presentaron avistamientos de esta especie de camarón (HernándezAcosta, com. pers.) (Fig. 2) y los cuales alcanzaban un costo de 10-20 USD pieza ${ }^{-1}$. Tomando en cuenta estos registros, aunado al interés científico y gubernamental de México por conocer a las especies exóticas invasoras que están siendo introducidas o detectadas en la región, se consideró relevante iniciar los estudios de $P$. monodon mediante la recopilación de información científica que documenten las capturas realizadas por pescadores ribereños en diferentes países en el Atlántico Americano. Esta recopilación no solo busca ser el primer paso para definir la posible distribución de $P$. monodon, sino que además busca atraer la atención de las autoridades científicas para desarrollar trabajos más intensivos sobre la presencia y efectos de las especies exóticas invasoras al medio ambiente. 


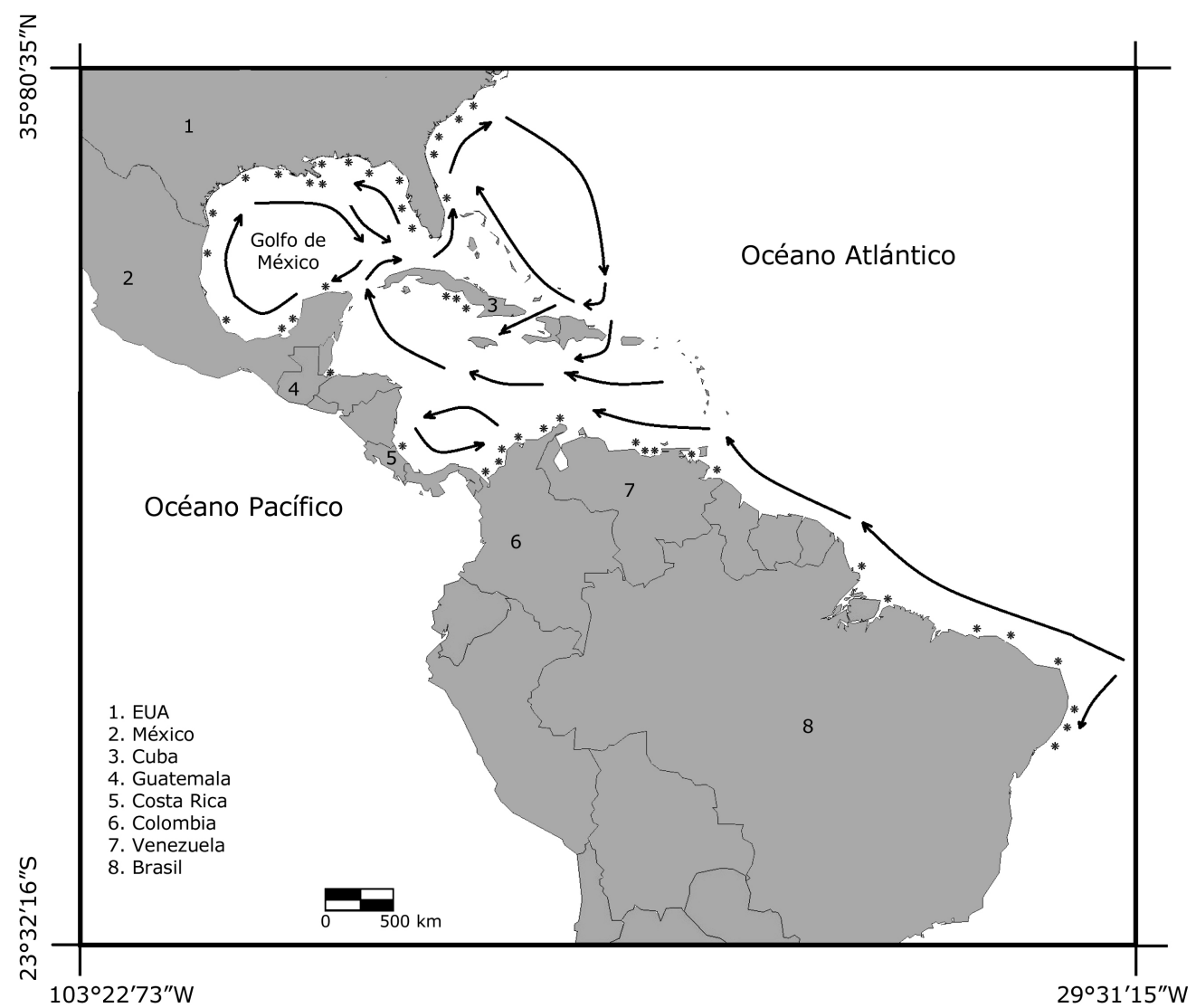

Figura 1. Detección de Penaeus monodon en el Atlántico Americano (*) y principales corrientes oceánicas en esta región (flecha) / Penaeus monodon detection in the American Atlantic $\left({ }^{*}\right)$ and principals ocean currents in this region (arrow)

\section{Características generales de PeNaEus monodon}

Penaeus monodon (Fabricius, 1798) es un peneido que posee un exoesqueleto quitinoso obscuro (cefalotórax y abdomen) con bandas transversales negras y blancas (Fig. 2). Dependiendo del substrato, alimento y turbidez del agua, los colores del cuerpo pueden cambiar a azul, café, gris, rojo, o verde, mientras que las bandas pueden tener colores como amarillo, azul o negro (Kongkeo 2005). Esta especie de decápodo se localiza en agua marina tropical con temperatura de 18 a $34,5{ }^{\circ} \mathrm{C}, 5$ a 35 de salinidad, y dependiendo de su estadio de desarrollo (postlarva a adulto) pueden estar a una profundidad de 1 a $100 \mathrm{~m}$. Son organismos de hábitos nocturnos, enterrándose en el sustrato durante el día y emergiendo en la noche en búsqueda de alimento, siendo también un organismo de tipo depredador y carroñero-omnívoro (FAO 2007).

Penaeus monodon se reproduce en aguas oceánicas donde libera los huevos que eclosionan y forman un nauplio zooplanctónico que se caracteriza por varios eventos de metamorfosis durante su crecimiento (14 a 20 días) pasando del estadio nauplio (I-V) a protozoea (I-III) y mysis (I-III) (Guy \& Cowden 2014). Las corrientes desplazan a las mysis hacia los esteros y lagunas costeras donde se transforman a postlarvas bentónicas que encuentran refugio y alimento en las zonas protegidas de manglar y pastos marinos. Las postlarvas crecen hasta la talla de juvenil (6 meses, $33 \mathrm{~g}$ ) y las corrientes trasladan a los juveniles hasta la costa durante la marea baja, donde permanecen de 5 a 6 meses. En esta etapa, los órganos sexuales externos se desarrollan (télico y petasma en hembras o machos respectivamente), al término de este periodo de crecimiento, los organismos sub-adultos migran desde las lagunas costeras hacia el océano donde madura sexualmente (40 a $261 \mathrm{~g}$ ) y se reproducen (Dall et al. 1990, Kenway \& Hall 1999). Los machos maduran sexualmente a $35-40 \mathrm{~g}$ (peso total) y aproximadamente $13,4-14,0 \mathrm{~cm}$ de largo total (Kenway \& Hall 1999). Las hembras por su parte son de télico cerrado y maduran principalmente a $80-100 \mathrm{~g}$ (peso total) y $18,0-19,0 \mathrm{~cm}$ de largo llegando a producir de 250,000 a 750,000 de huevos por puesta dependiendo de la talla y peso (Kenway \& Hall 1999, FAO 2007, Kannan et al. 2015). 


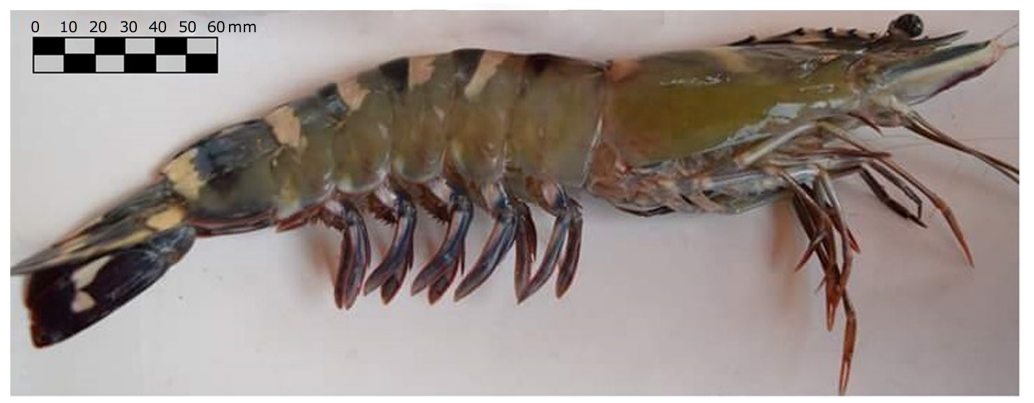

Figura 2. Espécimen de Penaeus monodon colectado en La Pesca, Soto La Marina, Tamaulipas, México. Fotografía cortesía del Dr. Mario Hernández-Acosta / Penaeus monodon collected specimen in La Pesca, Soto La Marina, Tamaulipas, Mexico. Photograph courtesy of Dr. Mario Hernández-Acosta

\section{Presencia de Penaeus monodon en América}

El camarón tigre asiático $P$. monodon es una especie nativa del Oeste del Indo-Pacífico con presencia en países como Australia, Bangladesh, Camboya, China, Corea, Filipinas, India, Japón, Madagascar, Malaysia, Nueva Guinea, Pakistán, Papua, Singapur, Sudáfrica, entre otros (Kongkeo 2005). Sin embargo, también ha colonizado el Mar Mediterráneo a través del canal de Suez (GómezLemos \& Hernando-Campos 2008, Giménez et al. 2014) y desde las últimas dos décadas ha sido capturado por pescadores ribereños y de alta mar en diversas zonas del Atlántico Americano (Tabla 2).

Diversos autores reportan que el ingreso de P. monodon hacia aguas del Atlántico Americano puede deberse a motivos tales como: i) transporte accidental de organismos en el agua de lastre de los barcos provenientes de Asía, ii) fugas en cultivos experimentales y/o comerciales desarrollados en diversos países de esta zona, o iii) migración natural de esta especie (Altuve et al. 2008, Gómez-Lemos \& Hernando-Campos 2008, Hidenburgo et al. 2011, Wakida-Kusunoki et al. 2013, 2016a; Fuller et al. 2014, Aguirre-Pabón et al. 2015, Avalos 2015). Una vez establecida la población de camarón, esta se reproduce y las corrientes y mareas naturales aumentan la dispersión de las larvas (Fuller et al. 2014, Aguirre-Pabón et al. 2015, Johnston \& Purkis 2015).

Los cultivos de $P$. monodon más antiguos fueron reportados por Welcomme (1988) y Villac et al. (2009) realizados en EUA y Panamá en 1976 y Brasil en 1977 (Tabla 1). Reportes de cultivos experimentales y comerciales serían en Cuba, EUA, y Venezuela a mediados de los '80s (Rodríguez \& Suárez 2001, Coto 2005, Giménez et al. 2013, Fuller et al. 2014, RodríguezAlmaraz \& García-Madrigal 2014). Rodríguez-Almaraz \& García-Madrigal (2014) y Avalos (2015) señalan que
P. monodon fue trasladado a Hawái, EUA para trabajos de investigación y Carolina del Sur, EUA en 1988 para actividades comerciales de acuacultura, respectivamente. En este último estado, se reportaron fugas de los camarones debido a daños en las instalaciones ocasionados por las tormentas tropicales Chris y Keith que afectaron a Carolina del Sur ese año, así como la tormenta tropical Hugo en 1989. Fuller et al. (2014) reporta la fuga de P. monodon en 1988 y señala comunicaciones personales que definen la recolecta de 300 organismos de esta especie de camarón por pescadores locales, sin que fueran nuevamente detectados hasta el 2006. Villac et al. (2009) indicaron la presencia de $P$. monodon en Brasil, sugiriendo que posiblemente provenían de organismos fugados de las granjas acuícolas en la zona de Río Potengí, Brasil en 1977. Esa especie de camarón fue detectada también en el complejo lagunar de Guaraíra, y estuario del río Curimataú, Brasil. Ambos resultados pueden sugerir que los organismos fugados lograron adaptarse, madurar y reproducirse en la zona.

La primera referencia de camarón P. monodon obtenido por pesca en las costas del Atlántico Americano, fue en Totoai, Maranhao, Brasil (Fausto-Filho 1987), una década después de ser usados en pruebas acuícolas en ese país. Fuller et al. (2014) reportan la presencia de esta especie de peneido en la costa de Alabama, Florida, Georgia, Las Carolinas, Luisiana, Mississippi y Texas, EUA en el 2006 y que su posible presencia puede deberse a las descargas de agua que usan de lastre los barcos provenientes de Asia o Sudamérica. Sin embargo, Gómez-Lemos \& HernandoCampos (2008), Rodríguez-Almaraz \& García-Madrigal (2014), y Avalos (2015) sugieren que los camarones $P$. monodon que escaparon en 1988 de granjas de cultivo presentes en esos territorios de los EUA puede ser otra de las posibles fuentes para la presencia de esta especie de crustáceo en la región Norte del Atlántico. 
Los reportes de introducción de $P$. monodon (Tabla 1), además del registro histórico de esta especie para las capturas incidentales en el Atlántico Americano (Tabla 2), la distribución de los organismos capturados y las corrientes existentes en la zona (Fig. 1) pueden sugerir que los camarones que se escaparon de los cultivos experimentales y/o comerciales hayan sido la opción más viable para comprender la presencia de esta especie de crustáceo en aguas del Atlántico, en comparación con los organismos que pueden llegar en las aguas de los lastres de buques cargueros. Además, es importante considerar que los organismos provenientes de estos cultivos experimentales y/o comerciales fueron aclimatados a las condiciones ambientales locales donde eran cultivados, factor que puede aumentar considerablemente la posibilidad de sobrevivencia en comparación a los provenientes de los lastres de buques.

Al observar los registros históricos de $P$. monodon (Coelho et al. 2001, Santos \& Coelho 2002, Silva et al. 2002, Tavares \& Braga 2004, Medellín et al. 2011, Aniceto et al. 2014, Sandoval et al. 2014, Morais et al. 2015, Zink et al. 2018) (Tablas 1 y 2) se puede indicar que hay más de una década entre la fuga y las primeras capturas de esta especie por pescadores ribereños y de altamar en el medio silvestre del Atlántico. A partir del 2000, se hizo frecuente la captura ocasional de esta especie de camarón en países como Brasil, Colombia, Costa Rica, Cuba, EUA, Guatemala, México y Venezuela (Tabla 2, Fig. 1). Inicialmente, se detectaba la presencia ocasional de ejemplares adultos, pero hoy en día se ha vuelto más común la colecta de estos organismos. Esto puede sugerir la permanencia y dispersión de la población de P. monodon en costas del Atlántico Americano (Altuve et al. 2008, Giménez et al. 2013).

\section{Origen potencial de Penaeus monodon en EL AtLÁntico Americano}

Aguirre \& Chasqui (2014) y Aguirre-Pabón et al. (2015) emplearon la genética como herramienta para determinar el posible origen de los camarones $P$. monodon detectados en Colombia. Se realizaron estudios de diversidad y relación genética en especímenes colectados y comparando la región control del ADN mitocondrial (ADNmt-CR) con 342 secuencias obtenidas a través del GenBank provenientes de muestras originales de $P$. monodon del Indo-Pacífico. El análisis reveló halotipos que tienen una fuerte relación con las poblaciones de este camarón presentes en China, Filipinas y Taiwán. Cabe mencionar que Wyban \& Arki (1989) y Junqueira et al. (2009) señalan que los camarones $P$. monodon cultivados en Hawái y Carolina del Norte, EUA en 1988, provenían de Taiwán y Filipinas, mientras que los que Brasil en 1977 provenían de Filipinas. Los organismos colectados no guardan un vínculo genético con la población de $P$. monodon de Madagascar y Sudáfrica (Aguirre-Pabón et al. 2015) que son las áreas de distribución biogeográfica natural más cercanas de esta especie de camarón al Atlántico Americano (Kongkeo 2005).

Debido a la ubicación geográfica de Tamaulipas, México en la costa Noreste del Golfo de México al igual que su cercanía con EUA (Fig. 1) se puede sugerir que los organismos detectados en esta región por WakidaKusunoki et al. (2013) y Acosta-Hernández (2016, com. pers) pueden provenir de EUA donde hay reportes del cultivo de esta especie, fugas y capturas en el medio silvestre en 1988 y 2006-2012 (Tabla 2). Una situación similar se reportas por Gómez-Lemos \& HernandoCampos (2008), Giménez et al. (2013) quienes sugieren esta posibilidad ante la presencia de $P$. monodon en las costas de sus respectivos países. A su vez Johnston \& Purkis (2015) señalan que la presencia de mero pantera [Chromileptes altivelis (Valenciennes, 1828)], camarón tigre asiático (P. monodon), pez murciélago [Platax orbicularis Linares, 1758)] y pez león [Pterois volitans Linares, 1758)] en las islas de Jamaica y Bahamas deriva de larvas provenientes de los EUA.

McCann et al. (1996) y Briggs et al. (2004) señalan que P. monodon no podría establecerse en aguas del Atlántico Americano. Sin embargo, la captura incidental de esta especie por pescadores ribereños y de altamar desde el 2000, la presencia de organismos silvestres adultos maduros capturados en Costa Rica (Alfaro-Montoya et al. 2015) y la detección de hembras ovígeras de esta especie de crustáceo (Aguado \& Sayegh 2007) sugieren que este organismo se ha establecido en aguas del Atlántico Americano (Fuller et al. 2014, Aguirre-Pabón et al. 2015) y que se está dispersando hacia diferentes regiones. Esta sugerencia se refuerza con las colectas reportadas en distintos países (Tabla 2), la cual brinda también información sobre el sexo y tallas de los camarones $P$. monodon colectados por pescadores y donde se observa que estos organismos están cerca o dentro del rango de talla y peso para reproducirse $(35-40 \mathrm{~g}, 13,4-14,0 \mathrm{~cm}$ de largo para machos, y 80-100 g, 18,0-19,0 cm de largo para hembras) (Kenway \& Hall 1999). La dispersión de P. monodon desde las áreas donde se presentaron escapes de los cultivos experimentales y/o comerciales en América pudo deberse a las corrientes existentes en el Atlántico Americano complementadas con las generadas durante las tormentas y huracanes. Esta idea sugerida por Johnston \& Purkis (2015) para explicar cómo P. monodon logró llegar desde Florida, EUA y la isla de Las Bahamas. Un fenómeno similar de dispersión se observa con el pez león ( $P$. volitans) el cual escapó en 1985 de cultivos comerciales de peces de ornato en Florida, EUA y se ha distribuido a lo largo de la costa de ese país, además de México y números países 
de Centro y Sudamérica (Betancur et al. 2011, Reyes et al. 2014, Johnston \& Purkis 2015). Reyes et al. (2014) reportan que el pez león ( $P$. volitans) se dispersó a lo largo de las costas de Florida, EUA y desde ahí hacia Alabama, Mississippi, Georgia, Calorina del Sur, EUA, además de Bahamas, Cuba, Haití, Jamaica, República Dominicana, y Puerto Rico. Posteriormente, se distribuyó al Caribe, Sur de México, llegando hasta Sudamérica (Colombia, Venezuela, entre otras). Un factor que también favoreció la dispersión de ambas especies son las corrientes existentes en la zona (Fig. 1) ya que la dirección de estas fomenta la distribución de numerosas especies acuáticas, como lo sugieren Johnston \& Purkis (2015). Los registros históricos de $P$. monodon, las fugas de este organismo reportadas en documentos científicos, y los tipos de corrientes presentes en las costas del Atlántico (Tabla 2, Fig. 1) pueden sugerir que los camarones $P$. monodon fugados de Brasil generaron su distribución desde el Sur del Atlántico Americano hacia el Caribe, mientras que organismos fugados de EUA pueden ser la fuente de distribución desde el Norte del Atlántico Americano hacia el Caribe. Sin embargo, los reportes sobre la introducción de $P$. monodon para su uso en acuacultura en Cuba, Panamá, Venezuela y República Dominicana (Tabla 1) pueden ser otro elemento a considerar que fomento la presencia y dispersión de esta especie exótica invasora en aguas del Atlántico Americano, aun cuando no se han localizado reportes sobre la fuga de organismos en esos cultivos.

\section{EFECTOS EN EL MEDIO AMBIENTE}

La fuga de especies exóticas invasoras hacia ambientes nuevos donde carece de depredadores naturales y tienen una amplia gama de alimentos que puede favorecer la sobrevivencia y establecimiento de las mismas, convirtiéndolos en competidores y consumidores de la biota nativa. Penaeus monodon es una especie exótica que se escapó de las áreas de cultivo en 1988 hacia el Atlántico Americano y que ha sido detectada de forma regular desde el 2000 en esta región (Tabla 2). Contrariamente a lo sugerido por McCann et al. (1996) quienes señalaban que las condiciones ambientales existentes no favorecerían el establecimiento de esta especie de camarón. Hoy en día se desconoce el impacto que está generando $P$. monodon sobre la fauna nativa. Sin embargo, este camarón es un fuerte carnívoro y depredador de bivalvos, pequeños crustáceos y gusanos (Rodríguez \& Suárez 2001, Senanan et al. 2009, Wakida-Kusunoki et al. 2013. 2016a). Hill et al. (2017) señalan que, debido a ser preferentemente carnívoro, $P$. monodon fue un fuerte consumidor de jaiba azul Callinectes sapidus (Rathbun, 1896) y poliquetos (Capitellidae and Nereidae) en comparación de los camarones $F$. aztecus (Ives, 1891) y L. setiferus (Linneaus, 1776) y que son especies preferentemente omnívoras.

\section{EFECTOS EN LA SANIDAD ACUícola}

Las especies exóticas invasoras constituyen una amenaza ambiental al poder afectar la biodiversidad y sobrevivencia de las especies nativas mediante el tipo de patógenos (virus, bacterias, hongos y protozoarios) que pueden traer a nuevos ambientes (Rodríguez-Almaraz \& García-Madrigal 2014). Briggs et al. (2005) y Sánchez-Paz (2010) señalan que el síndrome de la mancha blanca (WSSV) se detectó originalmente en camarones cultivados en Taiwán en 1992 [P. monodon, M. japonicus, y Fenneropenaeus penicillatus (Alcock, 1905)] siendo posteriormente detectado en granjas de camarón (L. setiferus) en Texas, EUA en 1995 y demostrando además que L. vannamei y L. stylirostris eran susceptibles a infecciones ocasionadas por este patógeno. Nunan et al. (1998) realizaron estudios sobre la detección de virus de camarón en $P$. monodon congelados y colectados en supermercados de Arizona, Texas, y Washington, EUA detectando la presencia de WSSV en ellos. Se sugiere que el mecanismo de dispersión de este virus en diversos países de Asia fue a través de la importación de postlarvas infectadas de China, mientras que en América fue a través de la importación de camarón congelado de origen asiático para consumo humano y cuyos subproductos se emplearon en acuacultura o donde las aguas residuales de las plantas procesadoras eran desechadas al Atlántico donde el virus encontró hospederos en la fauna local de camarones.

Briggs et al. $(2004,2005)$ reportaron que la introducción de virus foráneos que afectaron al camarón en Hawái y EUA fue debido a la importación de camarón no nativos entre 1975 y 1988 con fines de investigación, siendo $P$. monodon una de las especies de camarón importadas a Hawái, EUA y posteriormente enviada a Carolina del Sur. Este fenómeno de transfaunación de agentes patógenos propicio que EUA detuviera la introducción de camarones con fines experimentales ante el temor de introducir más virus. Briggs et al. (2005) sugieren que el colapso en la producción de $P$. monodon de cultivo que presentó Asia pudo deberse a la entrada de IHHNV transportado por las importaciones de L. vannamei para determinar su potencial y adaptabilidad a la región asiática. Senanan et al. (2007) también sugieren que un elemento que favoreció la presencia de TSV en Asia pudo ser la introducción ilegal de L. vannamei para cultivo en esa región y que afectó significativamente la producción de camarón nativo empleado en China y Tailandia [F. chinensis (Osbeck, $1765)$ y $P$. monodon, respectivamente)]. Cabe señalar que TSV es un virus originario de América y que ahora está distribuido también por Asia. 


\section{ConClusión}

Las capturas reportadas de $P$. monodon silvestres por pescadores ribereños y de altamar a lo largo de estos años en el Atlántico Americano sugieren que esta especie de camarón se ha logrado establecer en esta región, siendo además las capturas cada vez más frecuentes lo que sugiere el crecimiento de esta población. Sería de gran valor científico realizar estudios con las empresas que capturan camarón en altamar a fin de determinar el tamaño de esta población y su posibles distribución y dinámica poblacional. Además, al tener $P$. monodon diferentes orígenes, como lo señala la bibliografía, se puede sugerir que la población puede incrementar su diversidad genética al entrar en contacto los diferentes genotipos. Se desconoce concretamente el impacto que esta especie invasora puede estar generando sobre las especies locales. Al ser una especie de gran tamaño y ser preferentemente carnívora, se puede suponer que es un fuerte competidor de alimento.

La gran demanda que existe por incrementar la producción de camarón de acuacultura para satisfacer a los consumidores ha propiciado que especies de interés comercial como L. vannamei, L. stylirostris, M. japonicus, y $P$. monodon, entre otros, sean movilizados y cultivados en regiones diferentes a sus áreas naturales. Propiciando con ello la trasnsfaunación de los agentes patógenos, donde $P$. monodon puede ser un elemento de riesgo importante en la dispersión de WSSV y el virus de la cabeza amarilla (YHV). Estos patógenos virales del camarón son originarios de la región asiática y causantes de colapsos en la industria de camarón de acuacultura en esa región.

Ante el riesgo que implican las especies invasores (fugas de los organismos invasores, trasporte de patógenos a nuevas regiones, perdida de material genético por hibridación de especies, extinción de especies nativas por depredación, etc.) resulta evidente y se sugiere que las investigaciones destinadas a mejorar la producción acuícola deberían estar enfocadas al desarrollo de especies locales más que al desarrollo de especies foráneas que pueden generar un efecto irreversible al medio ambiente y el colapso de algunas actividades acuícolas.

\section{Agradecimientos}

Se agradece a la Facultad de Medicina Veterinaria y Zootecnia de la Universidad Autónoma de Tamaulipas por el apoyo otorgado en el desarrollo del presente documento. De igual forma se agradece al Dr. Mario Hernandez Acosta (QEPD) por su ayuda en la colecta de información y material fotográfico.

\section{LiterATURA CITADA}

Aguado GN \& J Sayegh. 2007. Presencia del camarón tigre gigante Penaeus monodon (Crustacea, Penaeidae) en la costa del estado Anzoátegui, Venezuela. Boletín del Instituto de Oceanografía de Venezuela 46(2): 107-111.

Aguirre J \& L Chasqui. 2014. Informe técnico: Diversidad genética de Penaeus monodon en el Golfo de Morrosquillo, 26 pp. INVEMAR, Santa Marta.

Aguirre-Pabón JC, G Orozco \& JC Narváez. 2015. Genetic status, source and establishment risk of the giant tiger shrimp (Penaeidae: Penaeus monodon), an invasive species in Colombian Caribbean waters. Acta Biológica de Colombia 20(1): 117-127.

Alfaro-Montoya J, AM Monge-Ortiz, D MartínezFernández \& E Herrera-Quesada. 2015. First record of the nonindigenous Penaeus monodon Fabricius, 1798 (Penaeidae) in the Caribbean Sea of Costa Rica, Central America, with observations on selected aspects of its reproductive biology. BioInvasions Records 4(5): 217-222.

Altuve DE, LA Marcano, JJ Alió \& JP Blanco-Rambla. 2008. Presencia del camarón tigre Penaeus monodon (Fabricius, 1798) en la costa del delta del río Orinoco y Golfo de Paria, Venezuela. Memoria de la Fundación La Salle de Ciencias Naturales 68(169): 83-92.

Aniceto IH, C Soares, B Bentes \& KC de Araújo-Silva. 2014. Novos registros de camarão-tigre-gigante Penaeus monodon Fabricius, 1798, na Plataforma Continental Amazônica (Crustacea, Decapoda, Penaeidae). Biota Amazónica 4(2): 172-175.

Avalos CG. 2015. Presencia y biometría del camarón tigre, Penaeus monodon (FABRICIUS, 1798), en la bahía de Amatique, Izabal. Tesis de Licenciatura, Centro de Estudios del Mar y Acuicultura, Universidad de San Carlos de Guatemala, Guatemala, 45 pp.

Betancur R, A Hines, A Acero, G Ortí, AE Wilbur \& DW Freshwater. 2011. Reconstructing the lionfish invasion: insights into Greater Caribbean biogeography. Journal of Biogeography 38(7): 1281-1293.

Briggs M, S Funge-Smith, R Subasinghe \& M Phillips. 2004. Introductions and movement of Penaeus vannamei and Penaeus stylirostris in Asia and the Pacific. RAP publication 2004/10: 9-69. Regional Office for Asia and the Pacific, FAO, Bangkok / Rome.

Briggs M, S Funge-Smith, RP Subasinghe \& M Phillips. 2005. Introductions and movement of two penaeid shrimp species in Asia and the Pacific. FAO Fisheries Technical Paper 476: 1-57.

Coelho PA, MCF Santos \& M Ramos-Porto. 2001. Ocorrência de Penaeus monodon, Fabricius 1798, no litoral dos estados de Pernambuco e Alagoas (Crustacea, Decapoda, Penaeidae). Boletin Técnico Científico do Cepene 9(1): 149-153.

Coto MG. 2005. Visión general del sector acuícola nacional - Cuba. In: National Aquaculture Sector Overview Fact Sheets. Departamento de Pesca y Acuicultura de la FAO, Roma. <http://www.fao.org/fishery/countrysector/ naso_cuba/es> 
Dall W, J Hill, PC Rothlisberg \& J Staples. 1990. The biology of Penaeidae. In: Blaxter JHS \& AJ Southward (eds). Advances in Marine Biology 27: 251-377. Academic Press, New York.

FAO. 2007. Improving Penaeus monodon hatchery practices. Manual based on experience in India. FAO Fisheries Technical Papers 446: 42-48.

FAO. 2018. El estado mundial de la pesca y la acuicultura 2018. Cumplir los objetivos de desarrollo sostenible, 233 pp. FAO, Roma.

Fausto-Filho J. 1987. Registro da captura de Penaeus monodon Fabricius no litoral do estado do Maranhão, Brasil (Crustacea: Penaeidae). Arquivos de Ciências do Mar 26(1): 81-82.

Fuller PL, DM Knott, PR Kingsley-Smith, JA Morris, CA Buckel, ME Hunter \& LD Hartman. 2014. Invasion of Asian tiger shrimp, Penaeus monodon Fabricius, 1798, in the western north Atlantic and Gulf of Mexico. Aquatic Invasions 9(1): 59-70.

Giménez E, L Pérez, BJ Ceballos, I Fraga, R Jiménez, D Cabrera \& A Moreno. 2013. Capturado el camarón tigre Penaeus monodon (Fabricius, 1798) en las costas de Cuba. El Bohío 3(2): 28-32.

Giménez E, L Pérez, BJ Ceballos, D Cabrera, J Rodriguez \& R Almeida. 2014. The giant tiger prawn, Penaeus monodon, distribution (Fabricius, 1798) in the Cuban shelf. Perspectives and futures actions. Revista Cubana de Investigaciones Pesqueras 31(1): 30-35.

Gómez-Lemos LA \& N Hernando-Campos. 2008. Presencia de Penaeus monodon Fabricius (Crustacea: Decapoda: Penaeidae) en aguas de la Guajira Colombiana. Boletín de Investigaciones Marinas y Costeras INVEMAR 37(2): 221-225

Guy J \& K Cowden. 2014. Optimising mulloway farming through better feed and hatchery practices. Rural Industries Research and Development Corporation. RIRDC Publication 14/109: 1-102.

Hidenburgo I, A Cintra, K de Sá Paiva, M do NascimentoBotelho \& KC de Araújo-Silva. 2011. Presence of Penaeus monodon in the continental shelf of the State of Para, Northern Brazil (Crustacea, Decapoda, Penaeidae. Revista de Ciencias Agrarias 54(3): 314-317.

Hill JM, ON Caretti \& KL Heck. 2017. Recently established Asian tiger shrimp Penaeus monodon Fabricius, 1798 consume juvenile blue crabs Callinectes sapidus Rathbun, 1896 and polychaetes in a laboratory diet-choice experiment. BioInvasions Records 6(3): 233-238.

Johnston MW \& SJ Purkis. 2015. Hurricanes accelerated the Florida-Bahamas lionfish invasion. Global Change Biology 21(6): 2249-2260.

Junqueira AOR, MDS Tavares, Y Schaeffer-Novelli, VI Radashevsky, JO Cirelli, LM Julio, FR Romagnoli, KC dos Santos \& MAG Ferreira-Silva. 2009. Zoobentos. Em: Lopes RM, L Coradin, V Beck \& D Rimoldi (eds). Informe sobre as espécies exóticas invasoras marinhas no Brasil, pp. 145-339. Ministério do Meio Ambiente, Brasília.

Kannan D, P Thirunavukkarasu, SN Ashwinikumar \& N Shettu. 2015. Studies on maturation, spawning and hatching wild of shrimp Penaeus monodon Fabrics, 1798 collected from east coast of India. Journal of Aquaculture \& Marine Biology 2(5): 40-48.
Kenway MJ \& MR Hall. 1999. The supply of black tiger prawn broodstock for aquaculture. Austasia Aquaculture Magazine 13: 38-48.

Kongkeo H. 2005. Programa de información de especies acuáticas. Penaeus monodon. In: Programa de información de especies acuáticas. Departamento de Pesca y Acuicultura de la FAO, Roma. <http://www.fao.org/fishery/ culturedspecies/Penaeus_monodon/es>

Lightner DV. 2012. Development of specific pathogen free (SPF) shrimp stocks and their application to sustainable shrimp farming. In: Austin B (ed). Infectious disease in aquaculture: prevention and control, pp. 283-285. Woodhead Publisher, Cambridge.

McCann JA, L Arkin \& JD Williams. 1996. Nonindigenous aquatic and selected terrestrial species of Florida. Status, pathway and time of introduction, present distribution, and significant ecological and economic effects, pp. 132150. National Biological Service, Southeastern Biological Science Center, Gainesville.

Medellín J, L Gómez-Lemos \& A Gracia. 2011. Fichas de especies introducidas. En: Gracia A, J Medellín-Mora, DL Gil-Agudelo \& V Puentes (eds). Guía de las especies introducidas marinas y costeras de Colombia. INVEMAR, Serie de Publicaciones Especiales 23: 70-72. Ministerio de Ambiente y Desarrollo Sostenible, Bogotá.

Morais E, J Garcia, PV Nascimento, CE Rocha \& FA Morais. 2015. Second report of the occurrence of giant tiger prawn, Penaeus monodon Fabricius, 1798 (Crustacea: Decapoda), in Rio Grande do Norte state, Northeast Brazil. Arquivos de Ciências do Mar 48(2): 116-120.

Morán-Silva A, ML Jiménez-Badillo, S Cházaro-Olvera, C Meiners, G Galindo-Cortes \& JL Oviedo. 2014. First record of tiger shrimp (Penaeus monodon Fabricius, 1798), in the South-Central coast of Veracruz, Gulf of Mexico. Biocyt 7(28): 509-514.

Nielsen L, W Sang-Oum, S Cheevadhanarak \& TW Flegel. 2005. Taura syndrome virus (TSV) in Thailand and its relationship to TSV in China and the Americas. Diseases of Aquatic Organisms 63(2-3): 101-106.

Nunan LM, BT Poulos \& DV Lightner. 1998. The detection of white spot syndrome virus (WSSV) and yellow head virus (YHV) in imported commodity shrimp. Aquaculture 160(1): 19-30.

Reyes H, D Petatán, SM Melo \& H Pérez. 2014. Análisis del nicho ecológico y la distribución geográfica del pez león Pterois volitans / miles, en el Atlántico occidental. En: Low AM, PA Quijón \& EM Peters-Recagno (eds). Especies invasoras acuáticas: casos de estudio en ecosistemas de México, pp. 253-270. Secretaría de Medio Ambiente y Recursos Naturales, México.

Rodríguez G \& H Suárez. 2001. Anthropogenic dispersal of decapods crustaceans in aquatic environment. Interciencia 26(7): 282-288.

Rodríguez-Almaraz GA \& MS García-Madrigal. 2014. Crustáceos exóticos invasores. En: Mendoza R \& P Koleff (eds). Especies acuáticas invasoras en México, pp. 347371. Comisión Nacional para el Conocimiento y Uso de la Biodiversidad, México. 
Ruangsri J, S Kiriratnikom, N Sukrakanchana, S Arunrat, N Sukasem, T Klowklieng, J Kasornchandra \& K Supamattaya. 2005. Prevalence of Taura syndrome virus (TSV) and Infectious hypodermal and haematopoietic necrosis virus (IHHNV) in white shrimp (Penaeus vannamei) populations and susceptibility to infection of some aquatic species native to Thailand. Songklanakarin Journal of Science and Technology 27(1): 215-224.

Sánchez-Paz A. 2010. White spot syndrome virus: an overview on an emergent concern. Veterinary Research 41(6): 43. $<$ doi:10.1051/vetres/2010015>

Sandoval LA, J Leal-Florez, A Taborda \& JG Vásquez. 2014. Spatial distribution and abundance of the giant tiger prawn, Penaeus monodon (Fabricius, 1798), in the Gulf of Urabá (Caribbean), Colombia, South America. BioInvasions Records 3(3): 169-173.

Santos MCF \& PA Coelho. 2002. Introdução de espécies exóticas de camarões peneídeos (Penaeus monodon Fabricius, 1798 e Litopenaeus vannamei Boone, 1931) em ambientes estuarino e marinho do Nordeste do Brasil. Boletim Técnico Científico do CEPENE 10(1): 207-220.

Senanan W, N Tangkrock-Olan, S Panutrakul, P Barnette, C Wongwiwatanawute, N Niphonkit \& DJ Anderson. 2007. The presence of the Pacific whiteleg shrimp (Litopenaeus vannamei, Boone, 1931) in the wild in Thailand. Journal of Shellfish Research 26(4): 1187-1192.

Senanan W, S Panutrakul, P Barnette, S Chavanich, V Mantachitr, N Tangkrock-Olan \& V Viyakarn. 2009. Preliminary risk assessment of Pacific whiteleg shrimp (P. vannamei) introduced to Thailand for aquaculture. Aquaculture Asia Magazine 14(4): 28-32.

Shigueno K. 1985. Intensive culture and feed development in Penaeus japonicus. In: Taki Y, JH Primavera \& JA Llobrera (eds). Proceedings of the First International Conference on the Culture of Penaeid Prawns/Shrimps, pp. 115-122. Aquaculture Department, Southeast Asian Fisheries Development Center, Iloilo City.

Silva KCA, M Ramos-Porto \& IHA Cintra. 2002. Registro de Penaeus monodon Fabricius, 1798, na plataforma continental do estado do Amapá (Crustacea, Decapoda, Penaeidae). Boletim Técnico Científico do Cepnor 2(1): 75-80.

Tavares M \& J Braga. 2004. Introdução de crustáceos decápodes exóticos no Brasil: Uma roleta ecológica. Em: Salles J \& RS Corrêa (eds). Água de lastro e bioinvasão, pp. 59-76. InterCiência, Rio de Janeiro.
Tookwinas S, K Chiyakum \& S Somsueb. 2005. Aquaculture of white shrimp Penaeus vannamei in Thailand. In: Regional technical consultation on the aquaculture of $P$. vannamei and other exotic shrimps in Southeast Asia, Manila, Philippines, pp. 74-80. SEAFDEC Aquaculture Department, Tigbauan, Iloilo.

Villac MC, RM Lopes, ING Rivera, RT Bassanello, DR Cunha, JE Martinelli \& DB Santos. 2009. Plâncton. Em: Lopes RM, L Coradin, V Beck \& D Rimoldi (eds). Informe sobre as espécies exóticas invasoras marinhas no Brasil, pp. 39-95. Ministério do Meio Ambiente, Brasília.

Wakida-Kusunoki AT, LE Amador-del Angel, P CarrilloAlejandro \& C Quiroga-Brahms. 2011. Presence of Pacific white shrimp Litopenaeus vannamei (Boone, 1931) in the Southern Gulf of Mexico. Aquatic Invasions 6(Suppl. 1): $139-142$.

Wakida-Kusunoki AT, RI Rojas-González, A GonzálezCruz, LE Amador-del-Ángel, JL Sánchez-Cruz \& NA López. 2013. Presence of giant tiger shrimp Penaeus monodon Fabricius, 1798 on the Mexican coast of the Gulf of Mexico. BioInvasions Records 2(4): 325-328.

Wakida-Kusunoki AT, D Anda-Fuentes \& NA López-Téllez. 2016a. Presence of giant tiger shrimp Penaeus monodon (Fabricius, 1798) in eastern Peninsula of Yucatan coast, Mexico. Latin American Journal of Aquatic Research 44(1): 155-158.

Wakida-Kusunoki AT, HA Medina-Quijano \& RI RojasGonzález. 2016b. Presence of tiger shrimp Penaeus monodon in the Chelem lagoon, Yucatan, Mexico Ciencia Pesquera 24(2): 53-57.

Welcomme RL. 1988. International introductions of Inland aquatic species. FAO Fisheries Technical Paper 294: 1-318.

Wyban J. 2010. Shrimp farming diversification with SPF blue shrimp in Thailand. AQUA Culture Asia Pacific Magazine 6(6): 8-12.

Wyban JA \& C Arki. 1989. Aquaculture in Hawaii: past, present and future. Advances in Tropical Aquaculture 9(4): 37-43.

Zink IC, TL Jackson \& JA Browder. 2018. A note on the occurrence of non-native tiger prawn (Penaeus monodon Fabricius, 1798) in Biscayne Bay, FL, USA and review of South Florida sighting and species identification. BioInvasions Records 7(3): 297-302.

Recibido el 16 de abril de 2019 y aceptado el 10 de junio de 2020

Editor: Claudia Bustos D. / Colaborador editor: Armando Wakida K. 